\title{
Transformational supply chains and the 'wicked problem' of sustainability: aligning knowledge, innovation, entrepreneurship, and leadership
}

H.C. Peterson

EDITORIAL

Michigan State University, Product Center for Agriculture and Natural Resources, Homer Nowlin Chair of Consumer-Responsive Agriculture,USA; peters17@msu.edu

\begin{abstract}
Supply chains are increasingly asked by consumers, policy makers, and other stakeholders to deliver product attributes that range far beyond the experience and search attributes of classical consumer demand. One name given these attributes is credence attributes (e.g. place-of-origin, organic, locally-grown). Sustainability as an attribute is an interesting emerging case. Sustainability is an example of a 'wicked problem': complex, ill-defined, messy and unsolvable in any traditional sense. Sustainability's lack of tractability raises the interesting question as to how a supply chain or network produces a thing that is beyond conventional notions of definition and structure. The paper develops a general framework for linking supply chain performance to types of knowledge and supply chain governance. The framework draws from knowledge management theory, the resource based theory of the firm, and transactions cost economics. Various types of knowledge are argued to have different levels of strategic value - explicit knowledge has limited strategic value, tacit knowledge has moderate strategic value, and new knowledge has high strategic value. Managing wicked problems requires a type of supply chain governance that creates new knowledge in the context of a broad stakeholder network. This type of governance is called transformational and is contrasted with exchange governance and learning governance. Once developed, the framework is applied to the wicked problem of sustainability, including a case study on one empirical structure being used to manage it. For supply chains and networks, future economic value is likely to demand delivery of more and more complex attributes that will take businesses increasingly into the realm of wicked problems.
\end{abstract}

Keywords: sustainability, supply chain management, knowledge management, transformational governance, strategic value of knowledge, product attributes

\section{Introduction}

Supply chains are increasing asked by consumers, policy makers, and other stakeholders to deliver product attributes that range far beyond the experience and search attributes of classical consumer demand. One name given these attributes is credence attributes (e.g. place-of-origin, organic, locallygrown, environmental-friendly and fair trade). Demand for these attributes is increasing rapidly (e.g. Nimon and Beghin, 1999; Loureiro and Umberger, 2007; Basu and Hicks, 2008; Darby et al., 2008; Kanter et al., 2008; Frolich et al., 2009). They are challenging to deliver in that they can not be immediately examined in the product nor directly experienced in the product's use. Rather they come from some form of value about how the product is produced, processed, distributed, etc. Sustainability as an attribute is an interesting emerging case. A business decision-maker's immediate inclination is to think of it as just another credence attribute. But such thinking belies the highly complex nature of sustainability versus something similar to organic or locally-grown. As will be argued, sustainability is an example of what is called a 'wicked problem' (Rittel and Webber, 1973; Conklin, 2006) ${ }^{1}$. Wicked problems are complex and messy, characterised by several features: no definitive formulation of the problem exists; its solution is not true or false, but rather better or worse; stakeholders have radically different frames of reference concerning the problem; constraints and resources for solution change over time; and, the problem is never solved. However messy something such as sustainability may be as a wicked problem, it seems highly desired by certain consumers today, and it has recently crept into product advertising campaigns. Just google the term and millions of references can be had in an instant. Sustainability's lack of tractability raises the interesting question as to how anyone produces a thing that is beyond conventional notions of definition and structure.

\footnotetext{
${ }^{1}$ The author wishes to thank his colleague Dr. Sandra Batie for the suggestion to incorporate the concept of wicked problems into the paper and for other helpful feedback. Thanks is also extended to doctoral student Adam Lovgren for assistance in literature review and editing, and to related helpful reviews from Dr. Henk van Latesteijn, Dr. Hamish Gow, and Dr. Michael Hamm.
} 
Other such wicked problems (e.g. climate change, food and fuel competition) are lurking in the wings for supply chains and networks to respond to with products and services. How are such problems recognised? Are they in any sense manageable? How? Under what circumstances? This paper explores wicked problems and suggests how supply chains/ networks might manage them. (Note use of the word 'manage' rather then 'solve').

The paper develops a general framework for linking supply chain performance to types of knowledge and to types of supply chain governance. In the final analysis, managing wicked problems requires a type of supply chain governance that creates new knowledge in the context of a broad stakeholder network. The general framework is developed using the concepts of knowledge, innovation, entrepreneurship, and leadership. It draws from knowledge management theory, the resource based theory of the firm, and institutional economics. Once the general framework is laid out and justified, it is then applied to the wicked problem of sustainability, including a case study on one empirical structure being used to manage it. This paper is a conceptual outing. It is exploratory. The problem is worth our attention given that value has mostly been extracted from the low hanging fruit of simple product attributes (search and experience). Future economic value is more likely to demand delivery of more and more complex attributes that will take businesses increasingly into the realm of wicked problems (Camillus, 2008).

\section{Supply chain performance}

Supply chain performance can be conceived as having many possible and equally legitimate dimensions (see for example, Gow et al., 2002; Koops et al., 2002; $\mathrm{Ng}$ et al., 2003; Trienekens et al., 2003; Harrison and New, 2002). For this purpose, presume that all such dimensions can be represented by just two. One dimension is responsiveness the ability to deliver product or service benefits of value to targeted final consumers. The other dimension is efficiency - the ability to deliver any given set of benefits at the best possible price or cost. Together these two performance dimensions represent the fundamental elements of consumer value - perceived product benefit (marginal utility) compared to product price.

Part of responding to wicked problems is a realisation that a subset of a product's targeted final consumer base may be actors who do not actually consume the product in any traditional sense. These stakeholders in the product process may include non-governmental organisations (NGOs) that advocate definitions of the problem and its solution (e.g. Greenpeace, World Wildlife Federation), governmental bodies that may have a say in regulation, and third-party certifiers that may act as arbiters in the delivery process. Knowledge organisations (e.g. universities) may also play a role in developing information essential to product development and delivery. The key takeaway is that responsiveness and efficiency vis-a-vis wicked problems hinge on inputs from stakeholders well beyond the traditional notion of the supply chain's final consumers and the constituent firms in the supply chain.

If performance on either dimension of responsiveness or efficiency is less than desirable, the supply chain and/or its participant firms must create or alter strategies in order to improve performance. This is a rather obvious statement, but it sets up the next considerations - what is the relevant input into the strategy formation process, who provides it, and how is it provided.

\section{Knowledge as a critical input for performance improvement}

In the context of a general framework for enhancing supply chain performance, the role of knowledge as an input to strategy is argued here to be especially critical. It seems straightforward to argue that enhancing either dimension of supply chain performance (responsiveness or efficiency) requires knowledge.

The definitions for knowledge and types of knowledge are taken from the classic knowledge management work by Takeuchi and Nonaka (2000). Knowledge as used here is about beliefs and commitments; it is about action toward some end; and, it is about meaning that is contextspecific and relational (Takeuchi and Nonaka, 2000: 141). Knowledge is in this sense justified true belief (not truth in some objective disembodied sense). Existing knowledge is divided into two types: (1) tacit knowledge which is contextspecific and informal arising from experience and practice, and (2) explicit knowledge which is codified, rational, separable from context and thus transmittable by formal means, e.g. information systems, manuals.

For Takeuchi and Nonaka (2000), new knowledge is created by various forms of 'conversion' between tacit and explicit knowledge. Tacit knowledge becomes explicit through the process of externalisation, i.e. taking what is known from practice and experience and making it formal and accessible to others. The scientific induction is a form of externalisation. Tacit knowledge is converted into more tacit knowledge through the process of socialisation, i.e. sharing experiences and practice with others. Apprenticeship is an excellent example of socialisation. Explicit knowledge becomes tacit through a process of internalisation, i.e. taking explicit knowledge (from others) and applying it in one's own practice. Finally, explicit knowledge is converted to more explicit knowledge through combination, i.e. combining or 
synthesising different bodies of explicit knowledge. Formal education is an archetype of this knowledge conversion. Scientific deduction also fits here.

Takeuchi and Nonaka (2000) argue that organisations can use the two types of knowledge and the four conversion processes as the foundation for creating a spiral of organisational knowledge creation. To complete their model, a final dimension is added to the analysis called the knowledge level that moves from the individual being the knowledge holder through intra-organisational groups to the organisation itself and ending with inter-organisational holders, this latter category being of particular interest in the context of supply chains. As various forms of conversion between explicit and tacit knowledge occur across the various organisational levels, new knowledge is created, shared and acted upon.

The Takeuchi and Nonaka spiral can be uncoiled to examine the strategic value of the three types of knowledge being considered - explicit, tacit, and new. Strategic value equates to the economic rents earned from knowledge used to create competitive advantage (and associated enhancements of performance in responsiveness or efficiency). The resource based view of the firm posits that resources such as knowledge have value if they are scarce, imperfectly mobile, and protected from imitation or neutralisation by isolating mechanisms (Barney, 1991; Rumelt, 1984). If strategic value is the comparative dimension for knowledge, then the three types of knowledge form a continuum from explicit (low strategic value) through tacit (moderate strategic value) to new (high strategic value).

Explicit knowledge has low strategic value because it is easy to access given its codified form and thus easy to transfer and then internalise for tacit knowledge purposes. In this sense, explicit knowledge is neither scarce nor immobile. As a foundation for innovation, explicit knowledge's accessibility and transferability would help assure that all significant economic rent opportunities would be wrung out of it. However, technical innovation arising from combination might still be available but likely represents relatively simple application or transfer to new settings (i.e. some form of imitation). Explicit knowledge may have great tactical value in doing management and business tasks effectively and efficiently but it has little strategic value as a source of competitive advantage. In this sense, combining explicit knowledge leads to operational efficiency which is good and necessary, but not to strategically valuable innovation which implies a new value proposition created with a unique value chain. The one caveat to this analysis arises from the existence of isolating mechanisms, e.g. patents, trade secrets, that keep accessibility low even if the knowledge is explicit. However, patents expire and trade secrets are subject to exposure (e.g. a key employee shifts employers). On the whole, explicit knowledge has limited strategic value. It is commodity knowledge.

Tacit knowledge has moderate strategic value - more than explicit knowledge but less than new knowledge. It is only moderately accessible (less than perfect mobility) in that socialisation requires willing partners to share in the context in which the knowledge is relevant. As a source of innovation, tacit knowledge likely has more potential than explicit knowledge to spur innovation. Adaptations and enhancements to the tacit knowledge as it is externalised into explicit knowledge or as it is shared with other holders of distinct tacit knowledge would likely provide some fertile ground for valuable if constrained innovation (likely some scarcity effect). The lack of documentation for such knowledge becomes a part of its defence against imitation. The isolating mechanism of causal ambiguity (Rumelt, 1984) directly reflects the strategic value of tacit knowledge. Tacit knowledge is differentiated knowledge embedded in specific context, and thus it has more strategic value than explicit knowledge because tacit knowledge is necessary to construct a relatively different and distinct value chain. New knowledge has high strategic value. It is difficult to access in that it must be created before it can be used. No doubt it can arise from explicit and tacit knowledge but as previously argued such new knowledge would have at best moderate strategic value. Therefore, it is necessary to understand why Takeuchi and Nonaka's spiral can be uncoiled. There must be another source of new knowledge beyond what can be explained by the conversion of explicit and tacit knowledge. Knowledge was defined as justified true belief. New knowledge that could fuel breakthrough or newto-the-world innovation is most likely to come from outside the existing base of justified true belief. Paradigm shifts (Kuhn, 1962) or other radical changes in prevailing mental models will be the source of high value new knowledge. It cannot simply come from explicit and tacit knowledge alone although they may play some part in generating the paradigm shift. New knowledge creates the opportunity for first mover advantage based on transformational innovation. New knowledge is scarce, immobile (at least early in its life after discovery), and has its own isolating mechanism if properly managed as a first mover. New knowledge meets the definition of a strategically valuable resource because new knowledge is necessary to provide a new and unique value proposition.

Two other dimensions to the knowledge continuum are also critical to understand. Knowledge was defined as actionable - it must be in a form that is applicable to taking action. The risk associated with knowledge application to action need not be alike across the continuum. Explicit knowledge has relative certainty and high predictability in its application. Tacit knowledge is less certain and predictable given the 
potentially vague nature of socialisation as a conversion process or the potential to lack generalisation as it is externalised. New knowledge represents the greatest risk of applicability. New knowledge may even be beyond risk assessment as it may be uncertain and unpredictable until the new paradigm or other mental model shift that spawned it, is itself proven useful. These are essential characteristics of a true breakthrough innovation. New knowledge in this sense is neither explicit (justified by formal testing and documentation) nor tacit (justified by a cumulative body of practice).

Finally, the three types of knowledge are linked dynamically. As new knowledge is created it needs to be converted into some level of tacit knowledge (through internalisation) or explicit knowledge (through externalisation) to be fully useable. Valuable tacit knowledge ultimately needs to be converted into explicit knowledge to make it fully accessible. However, some tacit knowledge may never be made explicit, e.g. the inherent tacit knowledge of a true master craftsman. The hypothesis here is that nearly all knowledge decays with time to explicit knowledge. The strategic value of new knowledge is ultimately wrung out as it is applied and as others seek to copy it upon seeing its value in use. The rate of decay can be managed. A business that holds valuable knowledge will seek to protect the knowledge from decay (isolating mechanisms are all about doing this). A competitor business that does not hold the knowledge will seek to have that value decay quite quickly through imitation or substitute design. Academics actually want their new knowledge to decay immediately based on journal publication (scientific externalisation to explicit form). Another reason that knowledge decays to explicit is the incentive (even for its owner) to reap the great tactical value of explicit knowledge. Explicit knowledge allows for generational transfers from senior to junior employees. It allows knowledge institutions to train new employees at society's cost to support the infrastructure of the economy, and it allows operational efficiencies to emerge as the learning curve is descended. The learning curve itself is a function of the decay of new knowledge through tacit to explicit.

Table 1 summarises all the dimensions of the knowledge continuum. Now the analysis moves to further explore how knowledge gets harnessed in a supply chain setting to help respond to performance issues, most especially related to wicked problems.

\section{Harnessing knowledge across the supply chain}

Presume that decision makers within a supply chain are faced with a performance problem with regard to responsiveness, efficiency or both. The hypothesis is that a critical first assessment toward solving the problem is determining which type of knowledge (explicit, tacit, or new) will dominate in finding and implementing a solution. If much relevant explicit knowledge exists and is applicable, then explicit knowledge is the key. If solving the problem appears to hinge on context-rich, experiential knowledge, then tacit knowledge is the key. If little or no existing knowledge appears relevant to the solution, then new knowledge becomes critical. The assessment of what knowledge is needed is neither a trivial task nor a precise one. Some means of analysing the underlying cause of the performance concern would be required, and then a scan of the situation and potential options for solution would suggest what knowledge is

Table 1. The knowledge continuum based on strategic value.

\begin{tabular}{llll}
\hline Dimensions & Explicit knowledge & Tacit knowledge & New knowledge \\
\hline Accessibility & $\begin{array}{l}\text { Easy (codified; internalisation; unless } \\
\text { isolating mechanism, e.g. patent) }\end{array}$ & Moderate (socialisation) & $\begin{array}{l}\text { Difficult (creation precedes access; } \\
\text { time is needed for explicit testing } \\
\text { or tacit practice) }\end{array}$ \\
\hline $\begin{array}{llll}\text { Relevance to } \\
\text { innovation }\end{array}$ & $\begin{array}{l}\text { Technical innovation (application to } \\
\text { new settings) }\end{array}$ & $\begin{array}{l}\text { Adaptive innovation (adoption } \\
\text { with adaptation in new settings) }\end{array}$ & $\begin{array}{l}\text { Transformational innovation } \\
\text { (breakthrough or new-to-the- }\end{array}$ \\
\hline Application risk & Relatively certain, highly predictable & Moderately certain, predictable & Uncertain, unpredictable \\
\hline Dynamics & $\begin{array}{l}\text { Nearly all knowledge 'decays' to } \\
\text { explicit or becomes obsolete }\end{array}$ & $\begin{array}{l}\text { Becomes explicit through } \\
\text { externalisation (e.g. science) }\end{array}$ & $\begin{array}{l}\text { Becomes tacit through practice or } \\
\text { explicit through science }\end{array}$ \\
\hline Strategic value & $\begin{array}{l}\text { Low/limited (unless an isolating } \\
\text { mechanism) ‘Commodity' knowledge }\end{array}$ & $\begin{array}{l}\text { Moderate (causal ambiguity) } \\
\text { ‘Differentiated' knowledge }\end{array}$ & $\begin{array}{l}\text { High (first mover advantage) } \\
\text { 'Unique' knowledge }\end{array}$
\end{tabular}


required and available. An iterative assessment process would be highly likely as the assessment moves from initial stages to full understanding and problem solving.

After the initial assessment of which knowledge is needed, the next assessment is who holds the existing knowledge or who is best positioned to create the new knowledge. This assessment is based on Takeuchi and Nonaka's dimension of knowledge level (also referred to as the ontological dimension) ranging from individually held to intra-organisational group held to organisationally held to inter-organisationally (or multiorganisationally) held. Although knowledge held within a single organisation may be of substantial interest in its own right, any supply chain performance problem that can be solved within the confines of a single supply chain participant is not the issue of interest here. In Takeuchi and Nonaka's sense, the focus is on knowledge that needs to be shared inter-organisationally in order to solve a supply chain's performance problem. This need for interorganisational sharing of knowledge is a necessary condition to the remainder of the decision framework's development. Intuitively, if a supply chain performance problem can be traced, say to a single participant's inefficiency (unrelated to other participants' behaviour), then this is not a supply chain problem at all, and supply chain governance is not a significant issue beyond some likely market based discipline to get the one participant to enhance performance. The more interesting situation is when problems involve multiple supply chain participants and their respective knowledge sets, establishing the need for sharing and some form of collective action. Some form of system innovation thus becomes necessary to improve the performance of the multiple participants in the supply chain. The greater the scale and scope of system innovation needed, the more likely new knowledge will be essential to performance.

The third assessment in the problem solving process has two parts: what barriers exist to knowledge sharing or co-creation across the supply chain, and what incentives are essential to overcome the barriers. Given its relatively low strategic value and easy, low risk application, the sharing of explicit knowledge held by various supply chain participants would not appear to present many barriers. If isolating mechanisms such as patents exist, contracts for use are routinely negotiated and would not per se offer a particular barrier. In general, explicit knowledge would allow typical exchange or market based rules and powerful economic incentives to govern its sharing in the problem solving process.

The sharing of tacit knowledge provides a more challenging situation. Tacit knowledge has moderate strategic value to its holder and socialisation opportunities need to be created to convert it for supply chain use. The holder may behave opportunistically attempting to extract rents from other participants or fail to fully disclose the knowledge.
Incentives for sharing and opportunities for socialisation need to be created and enforced if the knowledge flow is to occur. A learning environment must be created to facilitate the conversion of tacit knowledge (through Takeuchi and Nonaka's socialisation and internalisation) leading to a solution for any performance problem.

The co-creation and sharing of new knowledge becomes the most challenging situation of the three. New knowledge has high strategic value, and who creates what share of the knowledge becomes a substantial potential source of barriers to achieving the needed knowledge creation. Again, potential opportunism by individual participants would be expected. The incentives for co-creation and sharing may not be clear and the uncertainty of application may muddle the entire process. Market-like exchange rules will not suffice, and socialisation (however strong) will also likely fall short. Yet another regime of coordination and incentives would need to be created - one with even stronger characteristics of managed or hierarchical coordination. Elements of a new regime would include creation of a shared value proposition, new process architecture to enable co-creation and sharing, and new business models to enable coordination and incentives.

\section{A framework linking supply chain performance, knowledge and governance}

These distinctions among the types of knowledge in regard to sharing, opportunism (e.g. rent seeking, moral hazard), coordination, and incentives are all the stuff of transaction cost economics, most especially Williamson (1975). The supply chain's governance structure will thus have a major influence on whether the transaction costs can be minimised and the knowledge flow needed for performance enhancement can occur. The three types of knowledge suggest three types of supply chain governance to be called, exchange governance, learning governance, and transformational governance. If the incorrect governance structure is in place, underinvestment in tacit and new knowledge would be predicted, and solving performance problems requiring tacit and new knowledge would be unlikely to occur.

Specifically, the various concepts of the paper can be brought together into a framework presented in Figure 1. The two performance dimensions of responsiveness and efficiency become the axes of the framework. Explicit, tacit and new knowledge are arrayed along the axes according to their strategic value (low to high) and thus related to the means of enhancing supply chain performance. The hypothesised three forms of supply chain governance are then presented in the areas related to their respective knowledge foundation. If a performance problem requires 
Supply Chain

Performance I:

Responsiveness

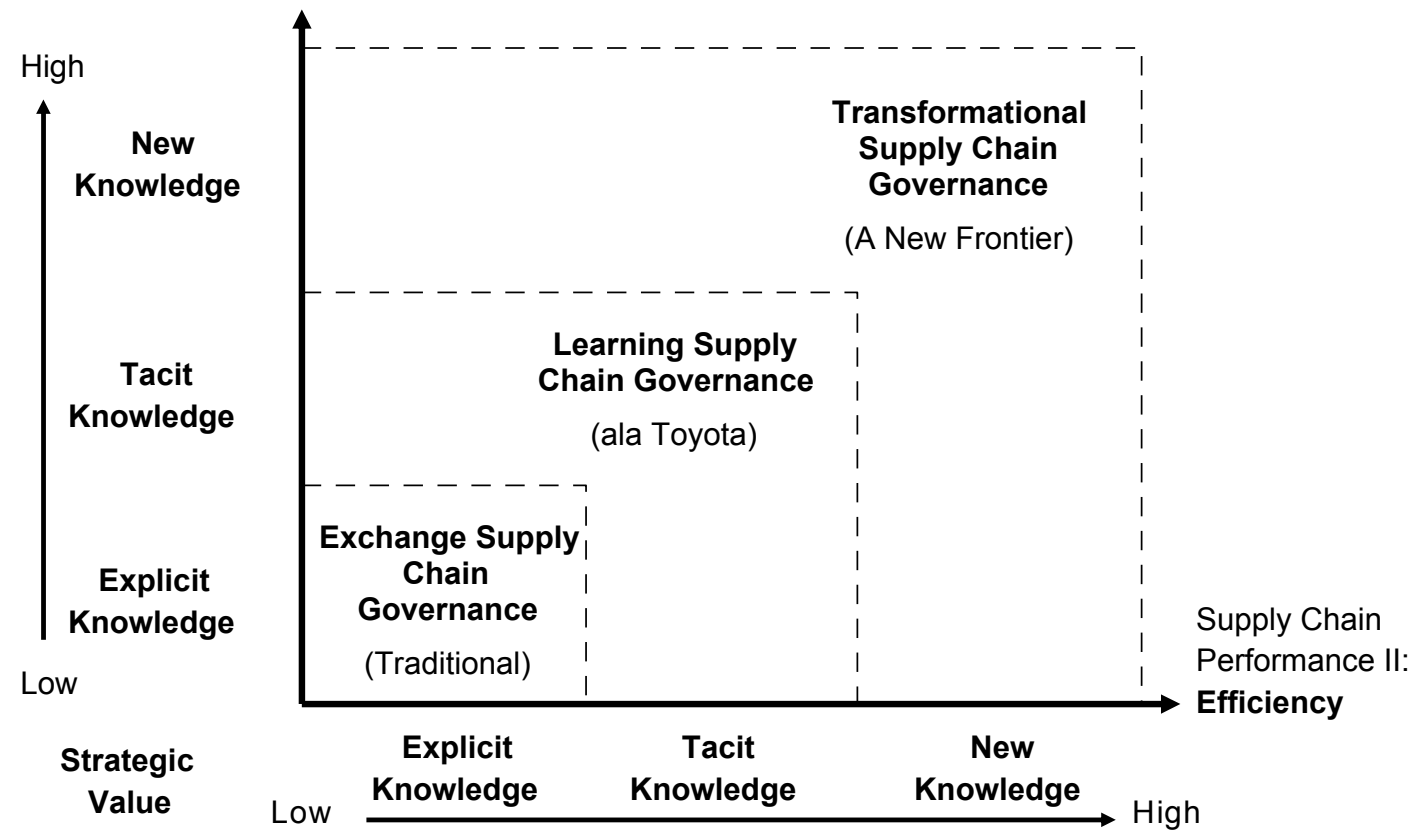

Figure 1. A framework for linking supply chain / network performance to knowledge and governance.

explicit knowledge to solve, then exchange governance should be applied. If a performance problem requires tacit knowledge, then learning governance should be applied. If a performance problem requires new knowledge, then transformational governance should be applied.

The framework of Figure 1 has little content without a clearer notion of what underlying processes lead to the effectiveness of each governance type. Table 2 presents a first cut at articulating the underlying processes for each. The knowledge foundation and incentive structure are present based on analysis already covered. The other three processes are necessary to complete the governance profile. Each governance structure should have a logically consistent means of:

1. Generating innovation consistent with its knowledge foundation.

2. Assuring entrepreneurial behaviour within and across supply chain participants to commercialise generated innovation.

3. Assigning supply chain leadership that appropriately coordinates the supply chain's governance and makes it effective.

In the presence of the appropriate knowledge, incentives, innovation process, entrepreneurship and leadership, a supply chain has the necessary and sufficient conditions to solve and implement strategies for supply chain performance enhancement. Consider the comparative governance features presented in Table 2.

Upon closer examination, exchange supply chain governance is simply traditional supply chain management in the form of classic logistics. The sharing of explicit knowledge via interconnected databases and formal sets of standards are well known to any student of supply chains. The sharing converts explicit to explicit knowledge through Takeuchi and Nonaka's process of combination. The incentive structure for sharing is based on exchange or market rules and is equivalent to the traditional notion of buying (rather than making), in this case the purchase is knowledge as it flows through the supply chain. The innovation process focuses on technical processes and their linkages, e.g. upgrading knowledge sharing interfaces along the supply chain. Entrepreneurship is handled by individuals within the firms with appropriate responsibility for internal implementation and coordination with similar individuals within other supply chain participants. Leadership would likely be provided by a supply chain captain or other directive leader in the strongest position to access and arbitrate the various needs for explicit knowledge.

Learning supply chain governance was a term developed and initially described by Peterson (Peterson, 2002; Sporleder and Peterson, 2003). Its tacit knowledge 
Table 2. Comparative governance features.

\begin{tabular}{|c|c|c|c|}
\hline Features & $\begin{array}{l}\text { Exchange supply chain } \\
\text { governance }\end{array}$ & Learning supply chain governance & $\begin{array}{l}\text { Transformational supply chain } \\
\text { governance }\end{array}$ \\
\hline Knowledge foundation & Explicit knowledge & Tacit knowledge & New knowledge \\
\hline $\begin{array}{l}\text { Incentive structure } \\
\text { for supply chain } \\
\text { collaboration }\end{array}$ & $\begin{array}{l}\text { Exchange based (market; 'buy' } \\
\text { knowledge externally) }\end{array}$ & $\begin{array}{l}\text { Relationship based (alliance; } \\
\text { 'share' knowledge under mutual } \\
\text { agreement) }\end{array}$ & $\begin{array}{l}\text { Co-creation based (managed; } \\
\text { 'make' knowledge internally to the } \\
\text { collaboration) }\end{array}$ \\
\hline Innovation process & $\begin{array}{l}\text { Comparing and contrasting } \\
\text { technical processes and their } \\
\text { linkages }\end{array}$ & $\begin{array}{l}\text { Mutual discovery as tacit } \\
\text { knowledge is shared and } \\
\text { reflectively analysed }\end{array}$ & $\begin{array}{l}\text { Mutual creation and evolution } \\
\text { through experimental design }\end{array}$ \\
\hline Entrepreneurship & Individual or intra-firm locus & $\begin{array}{l}\text { Individual and collective loci; } \\
\text { intra- and inter-firm }\end{array}$ & $\begin{array}{l}\text { Collective within and beyond } \\
\text { supply chain }\end{array}$ \\
\hline Leadership & $\begin{array}{l}\text { Leader-directed (hierarchical), } \\
\text { e.g. Supply Chain 'Captain' }\end{array}$ & $\begin{array}{l}\text { Leader-facilitated, e.g. supply } \\
\text { chain work associations ala Toyota }\end{array}$ & $\begin{array}{l}\text { Shared leadership, e.g. } \\
\text { collective engagement, network } \\
\text { management }\end{array}$ \\
\hline
\end{tabular}

foundation supports relationship based sharing built on Takeuchi and Nonaka's socialisation and internalisation processes. Incentives are governed by an alliance process that would develop rules for mutually agreed upon means of and rewards for sharing. Innovation is fuelled by mutual discovery as tacit knowledge is shared among the supply chain participants. Entrepreneurship occurs on both an individual basis and a more collective basis as individuals and groups of inter-organisational membership work together to commercialise innovation. Leadership would need to shift from directive to facilitative in order to assure that incentives were properly implemented and socialisation was fully participative.

Toyota's supply chain governance is a particularly relevant example of what would be expected of a learning supply chain. Dyer and Nobeoka (2000) present extensive case evidence that Toyota is a high-performance knowledgesharing network, i.e. a learning supply chain. Their case is made through a detailed examination of the various governance processes used by Toyota to establish and maintain the character of their supply chain network, most especially its focus on knowledge management. Network-level knowledge management processes include a supplier association, Toyota's operations management consulting division, voluntary small group learning teams, and inter-firm employee transfers. These are all examples of socialisation structures needed for tacit knowledge sharing. Undoubtedly strong integrated information technology systems also underlie this network for explicit knowledge transfer, but they are not argued to be the key to high performance. Dyer and Nobeoka also argue that two norms play a key role in knowledge management: (1) intellectual property rights reside at the network level rather than at the firm level and thus valuable knowledge must be shared if a firm is to remain a member of the supply network, and (2) the appropriable returns norm allows the recipient of knowledge from the network to appropriate $100 \%$ of the knowledge-created benefits in the short run. In regard to the second norm, only over time must the recipient share a proportion of those benefits with the network. For example, Toyota's consulting team shares valuable knowledge with suppliers, helps make changes, and allows the value of the benefits to remain with the supplier for some time before Toyota begins sharing them in the form of lower prices for components. These two norms establish the appropriate incentive structure for tacit knowledge sharing. Dyer and Nobeoka contrast Toyota's practice with General Motors more exchange oriented governance to show that GM's alternative norms do not result in the same two-way sharing of knowledge, either in breadth or depth, that emerges from the Toyota system.

Transformational supply chain governance is suggested as the new frontier. New knowledge is the knowledge foundation. The supply chain must thus create as well as share knowledge. Incentives must be in place to promote co-creation. These incentives will likely be specific to the situation and thus be uniquely managed. The goal is to make new knowledge internally to the collaboration of the supply chain participants. This process is not one of exchange or adaptive discovery; it is one of mutual creation, articulation and evolution. The environmental management literature also conceptualises this process as experimental adaptive management (Watzin, 2007) following a cycle of experiment, learn, adjust, and experiment again. 
Entrepreneurship must be a collective enterprise involving all relevant participants in the chain. Leadership needs to go beyond facilitative to co-led through a wide sharing of leadership tasks. Collective engagement better captures the quality of leadership desired (Fear et al., 2006).

Because new knowledge arises largely from new paradigms or new mental models, participation in transformational governance would potentially draw in a much broader group of participants than just the supply chain members. Knowledge institutions (e.g. universities and the academy more broadly) become potentially useful. NGOs that have insights into novel consumer demands or evolving social or environmental norms may become relevant as well. Governmental actors may also be needed to assure that the broader institutional setting would ultimately cooperate with and sanction new strategies that emerge. In short, transformational governance may require a fully open process (at least among relevant stakeholders) to achieve and implement new knowledge. The broader participation may also be essential to assure needed spreading of risk (given high levels of uncertainty) and buy-in by key stakeholders.

If successful, transformational governance can transform knowledge and supply chain relationships (thus the name transformational). However, the risks are high. Will new knowledge emerge? Will it be accepted by all key stakeholders? What incentives actually motivate the sharing of potential breakthrough, high-value knowledge? Who owns the new knowledge thus created? What happens if somewhere in the transformation process some current participant in the supply chain becomes clearly expendable to the new supply chain that must emerge? What if future supply chain performance hinges on an ever evolving set of knowledge, innovation and entrepreneurship because the problem being addressed is a wicked problem without solution? Would any such governance structure be stable or would its half-life be rather short? Having posited that such a governance structure is needed in a particular setting, this paper will leave the answers to all these questions as the suggested, robust research agenda for future work.

A framework for linking supply chain performance to knowledge and governance is now in place. The fundamental hypothesis taken from the framework is this: As the knowledge needed to enhance supply chain performance moves from explicit to tacit to new, the supply chain governance structure must move:

- From simple incentives to complex ones that motivate sharing and creating of ever more strategically value knowledge.

- From technical innovations through adaptive innovations to breakthrough innovations.
- From individualised entrepreneurship to collective entrepreneurship.

- From directive leadership to shared leadership.

In sum, governance must move from exchange governance to learning governance to transformational governance.

\section{Applications to sustainability}

The last task for this paper is providing an empirical example that motivates the need for the framework, suggests how it could be used, and provides support that transformational supply chain governance is possible in practice. The example is the wicked problem of sustainability.

Based on a synthesis of two separate sets of criteria (Rittel and Webber, 1973; Conklin, 2006), wicked problems can be characterised by several features:

- no definitive formulation of the problem exits;

- its solution is not true or false, but rather better or worse;

- stakeholders have radically different frames of reference concerning the problem;

- constraints and resources for solution change over time;

- the problem is never solved.

Sustainability fits all these criteria quite well. The concept of sustainability is by its most intuitive definition seductively simple. A use of resources today is sustainable if it does not constrain the use of resources tomorrow. This definition paraphrases the definition of sustainability development from the well-known United Nations Report 'Our Common Future' (1987). By this definition, consuming nonrenewable resources today constrains their use tomorrow because their supply is diminished without any reasonable prospect for replenishment. Consuming non-renewable resources is thus not sustainable. The definition is clear. The example is clear. The problem arises through the realisation that by this definition there is probably no use of resources that is sustainable. Every human use of a resource is less than $100 \%$ efficient, and the finite bounds of the earth suggest that eventually every resource will be exhausted. The discipline of economics takes as its founding principle the notion that resources are fundamentally scarce and must be used efficiently. Because the ideal is not likely attainable, sustainability is a matter of better or worse rather than true or false. To the extent that the bundle and mix of resources used across time changes (the stone age gives way to iron and then to steel; steam gives way to electricity; analog, land line communication gives way to digital wireless), the constraints on resource use will continually change over time and thus the 'solution' to sustainability will be constantly in flux. 
Once the definition of sustainability moves beyond the simple conversation of resources idea, there is no definitive formulation of what sustainability means and how it is achieved. Of popular appeal today is 'the triple bottom line.' Something is sustainable if it can achieve economic profitability, social justice, and environmental quality. Another express of this is the three Ps - Profit, People and Planet. But again, decision makers (public or private) are not given much content as to how one achieves the triple bottom line. One stakeholder or another is thus always in the position of saying to others that one or more of the dimensions of sustainability have not been achieved. Add to that the multiple perspectives (frames of reference) of the stakeholders and the problem becomes unsolvable. For example, business decision makers strongly tend to opt for prosperity first; environmentalists for planet; and, advocates of social justice for people. Each side has incentive to define sustainability by its own vocabulary consistent with its own end goals in mind.

Across all the criteria then, sustainability is an ideal example of a wicked problem. Given the definition of a wicked problem, the means to efficiently produce and deliver 'sustainable' products and services remains a challenging open question. The supply chain performance-knowledgegovernance framework of Figure 1 can assist in establishing a meaningful way forward to, at least, a manageable answer about means.

Applying the framework of Figure 1, the needed supply chain performance problem (producing and delivering sustainable products and services) involves both performance dimensions of responsiveness and efficiency. Responsiveness to consumers and related stakeholders requires product and service innovations that can be verified to be sustainable, while the participants in the supply chain are faced with implementing sustainable products and services in the most efficient manner possible. Success with responsiveness requires understanding and creatively combining consumer and stakeholder demands for sustainability to produce a responsive product or service. Success with efficiency hinges on minimising the cost of producing and delivering the responsive product or service. Working on one performance dimension without the other would certainly seem less than optimal (in this case, not sustainable). Further, enhancing performance in sustainability is a supply chain issue (and not merely an individual participant issue) because each and every member of the chain must contribute to sustainability in order to achieve it for the chain as a whole.

The next step to apply the framework is an assessment of what knowledge is needed to enhance performance. Given that sustainability has (a) no definitive formulation, (b) can only be thought of in degrees of better or worse, (c) has multiple frames of reference depending on stakeholder, (d) has evolving constraints and resource requirements, and thus (e) can never be solved, it is hard to imagine how existing knowledge, either explicit or tacit, can be properly brought to bear on producing or delivering sustainability. All existing knowledge must be suspect. It would seem that only new knowledge (breakthrough and paradigm shifting) co-created by stakeholders has any hope of resulting in a responsive and efficient set of products and services. Perhaps, the essential role of new knowledge is yet another trait that should be listed for wicked problems - wicked problems can only be effectively addressed by new knowledge.

To support the assertion that only new knowledge could work in the case of sustainability (or any other wicked problem), consider some expected non-productive behaviours by stakeholders predictable from the framework. First, each set of stakeholders would likely claim that its explicit knowledge is enough in itself to solve the dilemma. After all, if the solution is a matter of explicit knowledge, then exchange governance is all that is needed and the negotiations can begin over grades and standards, contracts, and terms of sale. Invoking science (the ultimate authoritative explicit knowledge in the western world) would be expected on all sides. Empirical observation of worldwide news media would clearly show that this predicted invocation has already occurred with great public declarations on all sides of the sustainability issue. A similar unproductive response would be that businesses in a supply chain would attempt to reduce sustainability to a traditional product attribute, and thus see it as a matter tractable by existing explicit knowledge of attributes, how supply chains produce them, and how consumer behaviour reacts to them. This delivery of sustainability would likely miss the point as a false drive for efficiency on the part of the supply chain would put the supply chain at risk of failing performance on responsiveness.

Second, if existing explicit knowledge is not invoked or is repudiated, then one would expect a similar claim that existing tacit knowledge is somehow enough to solve the problem. Various cases or archetype examples of sustainable or potentially sustainable supply chains would be invoked by one or another stakeholder. Socialisation processes could then be created to have the tacit knowledge transferred from practitioner to practitioner, or externalisation processes initiated to make the tacit knowledge explicit. The problem here with sustainability is that so little practice knowledge exists. There are examples of conservation practices, co-generation-of- energy practices, organic practices, benign environmental practices, or fair-trade-for-socialjustice practices. But none of these has been shown to be sustainable in regard to the triple bottom line or any other robust notion of sustainability. Existing tacit knowledge is woefully lacking. 
Given the likely failure of both explicit and tacit knowledge, new breakthrough knowledge stands alone as a possible input to managing the wicked problem of sustainability. Because new knowledge is needed to enhance both dimensions of performance, the framework of Figure 1 recommends transformational supply chain governance. It would seem that producing and delivering sustainability puts the supply chain as far out on the frontier of governance as any supply chain could get. But conceiving of such governance begs the question of whether such governance does or could exist. Within the author's experience, there is a candidate example that appears to fit the concept of transformational governance - a project within the Netherlands called TransForum. The author sits on the international advisory board of the project and has been involved since the project's early days in 1994. The goals, structure, and evolution of TransForum fit well with the transformational governance suggested in the final column of Table 2. The original goal of the project was to assist Dutch agriculture to become more sustainable. The project is a 50/50 (funding) partnership between the private sector and the public sector. Knowledge institutions in the form of several Dutch universities are involved, and a mix of projects (experiments) has evolved for developing new knowledge and innovation related to sustainability.

TransForum operates on the basis of five working hypotheses regarding sustainability and strategies that will move Dutch agriculture toward sustainability: '(a) sustainable development is a dynamic system property; (b) sustainable development needs system innovation; (c) system innovation is a non-linear learning process; (d) system innovation requires active participation of relevant key players from knowledge institutes, governmental bodies, civil society organisations and the business community; (e) the program requires transdisciplinary collaboration of all relevant players' (Van Latesteijn, 2008: 4). The sum of these working hypotheses imply both the nature of sustainability as a wicked problem (hypotheses a, b, and c), and key elements of a transformational governance structure (hypotheses $\mathrm{d}$ and $\mathrm{e}$ ).

TransForum sponsors three distinct types of projects. Collectively they have been designed to create new knowledge capable of creating common ground among the various stakeholders in agricultural sustainability. The project types are:

1. Practice projects (30 projects in total). These projects bring together the various stakeholder groups in an attempt 'to overcome obstacles (real problems) concerning system innovation which prevent the current agro-sector from becoming more sustainable' (Van Latesteijn, 2008: 9). The aim of each practice project is to develop shared value propositions among the stakeholders 'to ensure that People, Planet and Prosperity values are sustainably integrated in the agricultural production activity'. Each project has a guidance committee made up of the various stakeholders. The practical projects create new knowledge about new pathways to more sustainable development. New tacit knowledge also arises from the projects, as do new networks of scientists, practitioners, governmental officials, and civil society groups.

2. Scientific projects. These projects serve one of three purposes: (1) developing scientific solutions to problems arising in particular practice projects, (2) identification of system innovations and how they can be realised from across the entire body of practice projects, and (3) testing the TransForum's analytical framework of the five working hypotheses. These projects add to the credibility and validity of the new knowledge arising from the entirety of TransForum's work.

3. Learning projects. These projects combine learning from the first two sets of projects with reflection on 'developing the competencies and skills for innovation, and giving back and embedding these insights by means of learning arrangements and training programmes' (Van Latesteijn, 2008: 12) The findings from the learning and reflection are the elements for a new innovation system for agricultural sustainability.

The breakthrough systems innovation from the new knowledge generated by the collective projects has coalesced into the concept of Metropolitan Agriculture - a designed integrated system of agricultural production methods utilising new and intelligent connections between producers, sectors, raw materials, energy flows, stakeholders and other elements in order to sustainably fulfill the evolving demands on agriculture by a metropolitan society.

The breadth, depth and organisation of the entire range of projects sponsored by TransForum mirror the governance features of a transformational supply chain. New knowledge is the goal of the efforts. Incentives for co-creation are provided in the underlying structure (a participant's contribution gives it access to the knowledge gained). Innovation arises from mutual creation through experimental design. Entrepreneurship is collective involving all of the stakeholders. And, leadership is shared through the extensive guidance committee structure of TransForum.

At the same time, it appears to exemplify the best traits of transformational governance. TransForum is not itself a supply chain structure producing or delivering products and services in any conventional sense. However, the businesses within various Dutch agricultural supply chains initiated the efforts that became TransForum. Its projects span a number of different supply chains, and its results will potentially instruct all Dutch agricultural supply chains 
either domestically or globally given that the Dutch are integral to many international chains. TransForum thus provides both support for the existence of transformational governance and the concern that a supply chain may have to look beyond itself to an even broader structure to have transformational governance happen. In other words, TransForum may represent a neutral third party necessary to allow the sum of new knowledge creation activities to occur without incentive problems or opportunism getting in the way. This observation provides a further hypothesis for future study.

Other examples exist as candidates for transformational supply chains. The sugar cane industry in Brazil has evolving structures that would make it worthy of study as it transitions from a sugar-only industry to sugar, ethanol, and bio-electricity. Nestle's founding of its Sustainable Agriculture Initiative with a large number of European food firms as partners is another industry embedded structure to foster sustainable development throughout its agri-food supply chains. The Sustainable Michigan Endowed Project at Michigan State University has been experimenting and evolving toward structures to assist Michigan-based supply chains with sustainability. These three additional examples suggest that experimentation at the frontier of supply chain governance is emerging. Its ultimate success remains to be shown.

\section{Concluding thoughts}

As supply chains are motivated to produce and deliver ever more complex attributes for their consumers and other stakeholders, such chains will likely encounter product and service attributes that are not just attributes in any conventional sense (search, experience or credence) but arise from addressing wicked problems with no conventional definition and no closed-form solution. As a general concept, knowledge - explicit, tacit and new - is critical to enhancing any supply chain's performance in regard to responsiveness and efficiency. If explicit knowledge can solve performance concerns, then exchange supply chain governance is predicted to work. If tacit knowledge is essential, then learning supply chain governance becomes relevant. If new knowledge is critical, then supply chain governance must become transformational. In particular, wicked problems were argued to be manageable only with new knowledge co-created by a relevant network of supply chain stakeholders.

Sustainability was used as an archetypical example of a wicked problem: No definitive formulation of the problem exists; its solution is not true or false, but rather better or worse; stakeholders have radically different frames of reference concerning the problem; constraints and resources for solution change over time; and, the problem is never solved. TransForum was argued to be, at least, a protoexample of transformational governance. The breadth, depth, and organisation of its activities appear to align knowledge, incentives, innovation, entrepreneurship and leadership to make progress against the wicked problem of sustainability.

Perhaps this paper has raised more questions about transformational supply chain governance than it has answered. The paper was after all an exploration of both the frontier of supply chain governance and of wicked problems. The ultimate hope is that the paper creates curiosity about the problem and its management within the context of supply chains and networks. The research and practice motivated as a reaction will ultimately determine if the hope was reasonable and the proposed framework is a concept having intellectual and practical sustainability.

\section{References}

Barney, J., 1991. Firm resources and sustained competitive advantage. Journal of Management, 17: 99-120.

Basu, A.K. and R.L. Hicks, 2008. Label performance and willingness to pay for fair trade coffee: a cross-national perspective. Discussion Papers on Development Policy 125, Center for Development Research, Bonn, Germany.

Camillus, J., 2008. Strategy as a wicked problem. Harvard Business Review, 86 (5): 99-106.

Conklin, J.E., 2006. Dialog mapping: building shared understanding of wicked problems. CogNexus Institute, Naps, CA, USA.

Darby, K., M. Batte, S. Ernst and B. Roe, 2008. Decomposing local: a conjoint analysis of locally produced foods. American Journal of Agricultural Economics, 90 (2): 476-486.

Dyer, J.H. and K. Nobeoka, 2000. Creating and managing a highperformance knowledge-sharing network: the Toyota case. Strategic Management Journal, 21: 345-367.

Fear, F.A., C.L. Rosaen, R.J. Bawden and P.G. Foster-Fishman, 2006. Coming to critical engagement: an autoethnographic exploration. University Press of America, Lanham, MD, USA.

Froelich, E.J., J.G. Carlberg and C.E. Ward, 2009. Willingness-topay for fresh brand name beef. Canadian Journal of Agricultural Economics, 57: 119-137.

Gow, H.R., L.D. Oliver and N.G. Gow, 2002. Co-operating to compete in high velocity global markets: the strategic role of flexible supply chain architectures. Journal of Chain and Network Science, 2 (1): 19-32.

Harrison, A. and C. New, 2002. The role of coherent supply chain strategy and performance management in achieving competitive advantage: an international survey. The Journal of the Operational Research Society, 53 (3): 263-271. 
Kanter, C., K.D. Messer and H.M. Kaiser, 2008. Do rBST-free and organic milk stigmatize conventionally produced milk? Selected paper prepared for presentation at the American Agricultural Economics Association Annual Meeting, Orlando, FL, July 27 29, 2008.

Koops, S., D. Mollenkopf and T. Zwart, 2002. Food supply chains: are efficiency and responsiveness mutually exclusive? Journal of Chain and Network Science 2(1): 7-18.

Kuhn, T.S. 1962. The structure of scientific revolutions. University of Chicago Press, Chicago, IL, USA.

Loureiro, M.L. and W.L. Umberger, 2005. A choice experiment model for beef: what US consumer responses tell us about relative preferences for food safety, country-of-orgin labeling and traceability. Journal of Agricultural and Applied Economics, 37 (1): 49-63.

Ng, D., S. Sonka and R. Westgren, 2003. Co-evolutionary processes in supply chain networks. Journal of Chain and Network Science, 3 (1): 45-58.

Nimon, W. and J. Beghin, 1999. Are eco-labels valuable? Evidence from the apparel industry. American Journal of Agricultural Economics, 81 (4): 801-811.

Peterson, H.C., 2002. The 'learning' supply chain: pipeline or pipedream? American Journal of Agricultural Economics, 84(5): 1329-1336.

Rittel, H. and M. Webber, 1973. Dilemmas in a general theory of planning. Elsevier Policy Sciences, 4: 155-169.

Rumult, R.P., 1984. Towards a strategic theory of the firm. In: R. Lamb (ed.), Competitive strategic management. Prentice-Hall, Englewood Cliffs, NJ, USA, pp. 556-570.

Sporleder, T.L. and H.C. Peterson, 2003. Intellectual capital, learning, and knowledge management in agrifood supply chains. Journal on Chain and Network Science, 3(2): 75-80.

Takeuchi, H. and I. Nonaka, 2000. Theory of organizational knowledge creation. In: D. Morey, M. Maybury, and B. Thuraisingham (eds.), Knowledge management: classic and contemporary works. The MIT Press, Cambridge, MA, USA, pp. 139-182.

Trienekens, J., J. Hagen, A.J.M. Beulensc and S.W.F. Omta, 2003. Innovation through (international) food supply chain development: a research agenda. International Food and Agribusiness Management Review, 6 (1): 84-98.

United Nations, 1987. Our common future, report of the world commission on environment and development. Commission on Environment and Development. Published as Annex to General Assembly document A/42/427, Development and International Co-operation. August 2, 1987.

Van Latesteijn, H.C., A. Veldkamp, A.C. Van Altvorst, P.J. Beers, H. De Boon, R. Eweg, A. Fischer, E. Jacobsen, A. Van Kleef, S. Mager, H. Mommaas, P.J.A.M. Smeets, L. Spaans and J.C.M. Van Trijp, 2008. TransForum: organizing the transition towards Metropolitan Agriculture. TransForum, Zoetermeer, the Netherlands.
Watzin, M.C., 2007. The promise of adaptive management. In: M. Schnepf and C. Cox (eds.) Managing agricultural landscapes for environmental quality. Soil and Water Conservation Society, Ankey, IA, USA, pp. 147-158.

Williamson, O.E., 1975. Markets and hierarchies: analysis and antitrust implications. The Free Press, New York, NY, USA. 